\title{
Biomechanical properties of osteoporotic rat femurs after different hormonal treatments: genistein, estradiol, and estradiol/progesterone
}

\author{
İbrahim Azboy ${ }^{1, *}$, Mustafa Özkaya ${ }^{2}$, Teyfik Demir ${ }^{2}$, Abdullah Demirtaş ${ }^{3}$, Arslan Kağan Arslan ${ }^{4}$, \\ Emin Özkul ${ }^{1}$, Adnan Akcan ${ }^{1}$, and Tolga Tolunay ${ }^{4}$ \\ 1 Department of Orthopaedics and Traumatology, Dicle University, 2100 Diyarbakır, Turkey \\ 2 Department of Mechanical Engineering, TOBB University of Economics and Technology, 06560 Ankara, Turkey \\ 3 Department of Orthopaedics, Göztepe Training and Research Hospital, 34888 İstanbul, Turkey \\ 4 Department of Orthopaedics and Traumatology, Yenimahalle Training and Research Hospital, 06370 Ankara, Turkey
}

Received 8 October 2015, Accepted 22 March 2016, Published online 16 May 2016

\begin{abstract}
Introduction: The purpose of the study is to compare the effects of genistein, estradiol, estradiol/ progesterone combination on the bone mineral density and biomechanical properties of ovariectomized rats' bone. Methods: 50 female adult Sprague-Dawley rats were divided into five groups. Bilateral ovaeriectomy were performed in all groups except the sham-operated group. Groups were a sham-operated group and a control group (water was given), estradiol treated group (17- $\beta$ estradiol $0.015 \mathrm{mg} / \mathrm{kg}$ per day), genistein treated group (genistein $10 \mathrm{mg} / \mathrm{kg}$ per day), and an estradiol/progesterone combination group (17- $\beta$ estradiol $0.015 \mathrm{mg} / \mathrm{kg}$ plus drosperinone $0.028 \mathrm{mg} / \mathrm{kg}$ per day). The water or hormones were implemented in relevant groups for eight weeks by orogasthric catheter. The bone mineral density and biomechanical properties of the femur were analyzed.

Results: Genistein, estradiol, and estradiol/progesterone groups increased bone mineral density significantly compared to the control group. In diaphysis and metaphysis bending test, all groups had higher peak load values than the control group. There were statistically significant differences between the estrogen/progesterone group and control group in diaphysis bending with regard to peak load. There were statistically significant differences between the estradiol and control groups in metaphysis bending with regard to peak load. In axial rotation test, all groups had higher peak torque values than the control groups.

Conclusions: Genistein, estradiol and estrogen/progesterone combination improved the biomechanical properties of the ovariectomized rat bone. Genistein which has less side effects may be considered as an alternative in the treatment of postmenopausal osteoporosis.
\end{abstract}

Key words: Osteoporosis, Rat femur, Biomechanic, Genistein, Estradiol.

\section{Introduction}

Osteoporosis is a systemic disease characterized by reduced bone mass and structural deterioration of bone. Osteoporosis is a public health issue that affects the population over 50 years of age and postmenopausal women [1]. Estrogen replacement therapy (ERT) is effective in reducing or reversing bone loss [2-4].

ERT is associated with a higher risk for breast, endometrial, and ovarian cancer [5-9]. Persson's study [4] showed that replacement of Estrogen (EST) alone increased the risk of endometrial cancer. Replacement of EST with progesterone

\footnotetext{
*Corresponding author: ibrahimazboy@gmail.com
}

(PROG) reduced this higher risk [10-12]. Due to these side effects of long-term ERT use, the number of ERT users has fallen dramatically. Therefore, with the possible serious side effects of EST, there has been a growing interest in a substitute for EST with fewer side effects [13, 14]. Genistein (GEN), an isoflavone that is found abundantly in soybeans and their derivative food, could represent a natural alternative to ERT $[15,16]$. Structurally, it resembles $17-\beta$ estradiol and, as a natural selective estrogen receptor modulator, it can positively regulate bone cell metabolism without the potentially dangerous estrogenic effects on other tissues [17].

The purpose of this study was to assess the EST, GEN, and EST/PROG treatment in bilateral ovariectomized female rats. 
Diaphysis and metaphysis bending and axial rotation tests were performed to determine biomechanical properties of the rat's femur. To our knowledge, this is the first study which compares the effects of EST, EST/PROG, and GEN on biomechanical properties of the femur in ovariectomized rats.

\section{Materials and methods}

The study is approved by the local Animal Ethical Committee and carried out at our University Health Sciences Practice and Research Center. All experiments were performed in accordance with the National Health and Medical Research Council (NHMRC) guidelines for the use of animals for scientific research.

\section{Animals}

Fifty adult female Spraque-Dawley rats aged 12 weeks and weighing about $250-300 \mathrm{~g}$ were included in the study. The rats were kept at room temperature $\left(22 \pm 2{ }^{\circ} \mathrm{C}\right)$ with a photoperiod of $12 \mathrm{~h}$ light and $12 \mathrm{~h}$ dark cycle $(07.00 \mathrm{am}-07.00 \mathrm{pm})$. Throughout the experimental period standard pellet diet and water ad libitum were given to rats. Rats were anesthetized using ketamine $\left(50 \mathrm{mg} / \mathrm{kg}\right.$; intraperitoneal; Ketalar ${ }^{\circledR}$, Parke Davis, Eczacibasi, Istanbul, Turkey) and xylazine $(5 \mathrm{mg} / \mathrm{kg}$; intraperitoneal; Rompun ${ }^{\circledR}$, Bayer AG, Leverkusen, Germany). Midline abdominal incision was made at the pelvic level and bilateral ovariectomy (OVX) was performed in all groups except the sham-operated group.

\section{Randomization and treatments}

Twelve weeks after surgery the rats were randomly divided into five groups, each group including 10 rats. Water or hormones were injected in relevant groups for eight weeks by an orogastric catheter [18].

Group 1: (Sham group) and Group 2: (OVX group; control group); rats were given water once a day. Group 3: (OVX + EST group); rats received $17-\beta$ estradiol $0.015 \mathrm{mg} / \mathrm{kg}$ per day. Group 4: (OVX + GEN group); rats received GEN $10 \mathrm{mg} / \mathrm{kg}$ per day. Group 5: (OVX + EST/PROG group); rats received $17-\beta$ estradiol $0.015 \mathrm{mg} / \mathrm{kg}$ plus drosperinone $0.028 \mathrm{mg} / \mathrm{kg}$ per day [19].

After the end of the study, rats were sacrificed under general anesthesia. The uterus was weighed to confirm the success of ovariectomy. The femurs were freed from the skin, muscles, and tendons.

\section{Densitometry}

Freshly harvested bones were scanned using Dual-energy X-ray absorptiometry (DEXA). To ensure DEXA functionality, phantom calibration and quality assurance checks were also conducted prior to specimen scans. Bone mineral densities (BMD) of distal femur were measured using the accompanying small animal software.

\section{Biomechanical tests}

The femurs were stored at a temperature of $-40{ }^{\circ} \mathrm{C}$. The fixation dies were prepared to embed the femur samples before the tests. The femur was held by means of a clamp and the fixation depth was adjusted. Polymethylmethacrylate (PMMA) was used to embed the femurs through the dies. In the diaphysis bending test, only one side of the femur was embedded in PMMA. In the metaphysis bending test, femurs were not embedded in PMMA. After the embedding process, the specimen was kept at $-40{ }^{\circ} \mathrm{C}$ in a deepfreeze until the test to ensure the uniformity among the test samples' preparation. Before starting the test, femur specimens were thawed at room temperature for $12 \mathrm{~h}$, and physiologic serum was sprayed on the samples for hydration purposes.

\section{Axial rotation test setup}

To start the test, femur specimens were placed on the proper collets with the appropriate apparatus. One of the collets was fixed and contained a torque transducer. The other one was attached to the torque driver and it was allowed to rotate clockwise or counterclockwise. The Instron 55MT MicroTorsion Test machine was used for all tests. The schematic view of the test setup is shown in Figure 1. To ensure consistency, distal part of the specimens were placed in the torque driver side. After all pre-processing operations, the torque driver started to run. The torque driver twisted the femur specimens with a speed of $15 \mathrm{deg} / \mathrm{min}$. The test maintained until the breakage of femur occurred. During the test, torque and angle of twist values were recorded with the aid of data collector.

\section{Diaphysis bending test setup}

Test specimens for the diaphysis bending test were embedded into PMMA at the distal end. Specimen was fixed to the diaphysis bending test setup as shown in Figure 2. Bending compression was applied with $2 \mathrm{~mm} / \mathrm{min}$ constant crosshead speed. Failure criterion was the breakage of the rat femur. Diaphysis bending test was completed with the aid of an Instron 3300 testing machine. Yield load, yield displacement values, peak load, and peak displacement were recorded by the data collector. Stiffness values were calculated by using those values.

\section{Metaphysis bending test setup}

The aim of the test was to measure the three-point bending stiffness and strength of the femur. Specimens were placed on supports at the metaphysis. The bending test setup is shown in Figure 3. The test machine, crosshead speed, and failure criterion were the same as the diaphysis bending test. Peak load and peak displacement were recorded by the data collector. Stiffness values were calculated by using those values.

All biomechanical tests were repeated five times for each test group. The values in the results tables include the mean and standard deviation of those five values. 


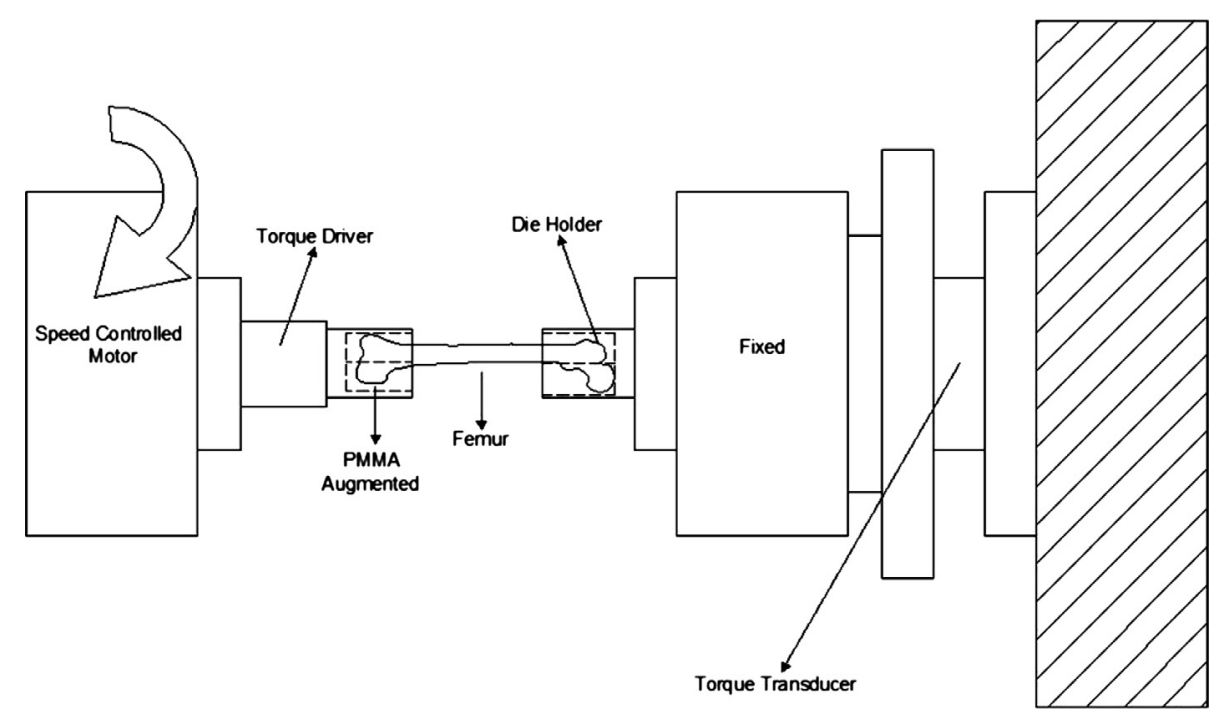

Figure 1. Axial rotation test setup.

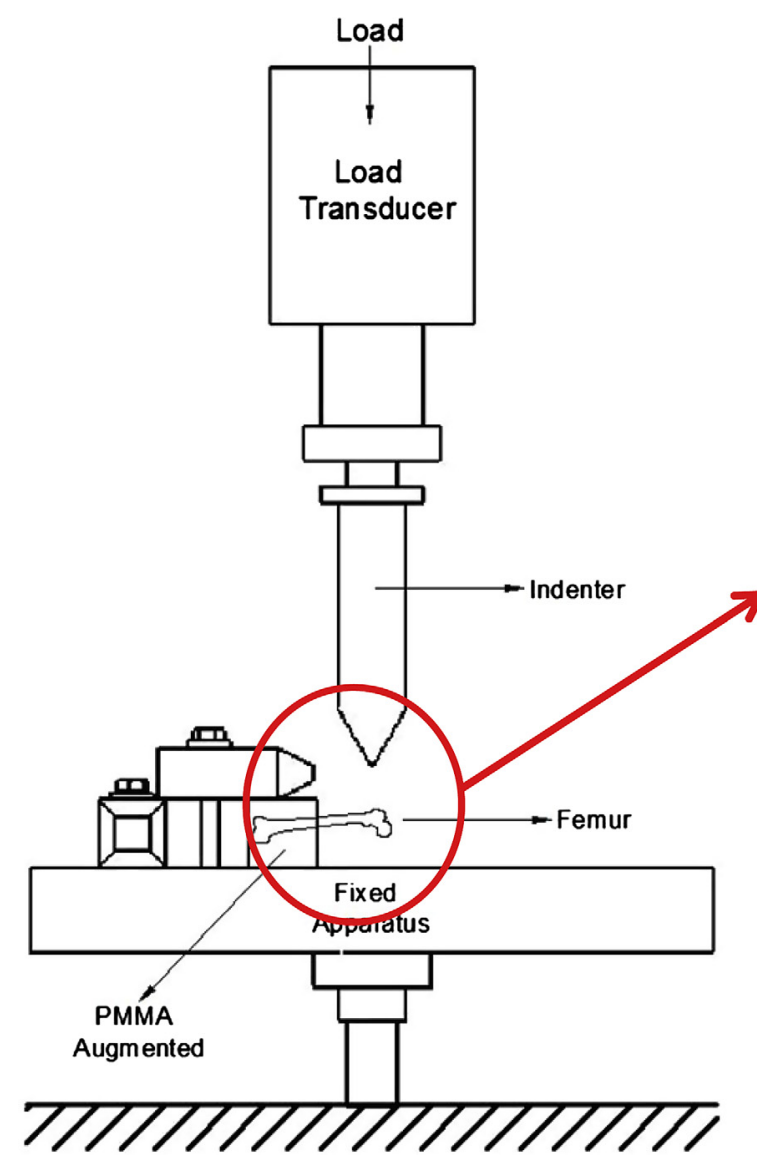

Figure 2. Diaphysis bending test setup.

\section{Statistical analyses}

A one-way ANOVA was performed to ascertain the treatment effect difference between the groups at an $\alpha=0.05$ level. If the ANOVA test was significant, Dunnett's test (when the variances were assumed to be equal) or Dunnett's T3 test (when the variances were assumed to be unequal) was applied to perform post hoc pairwise comparisons at $\alpha=0.05$ level. For statistical analysis the Statistical Package for Social Sciences (SPSS Inc., Chicago, IL, USA) v. 18.0 for windows software was used. A $p$ value $<0.05$ of was considered statistically significant. 


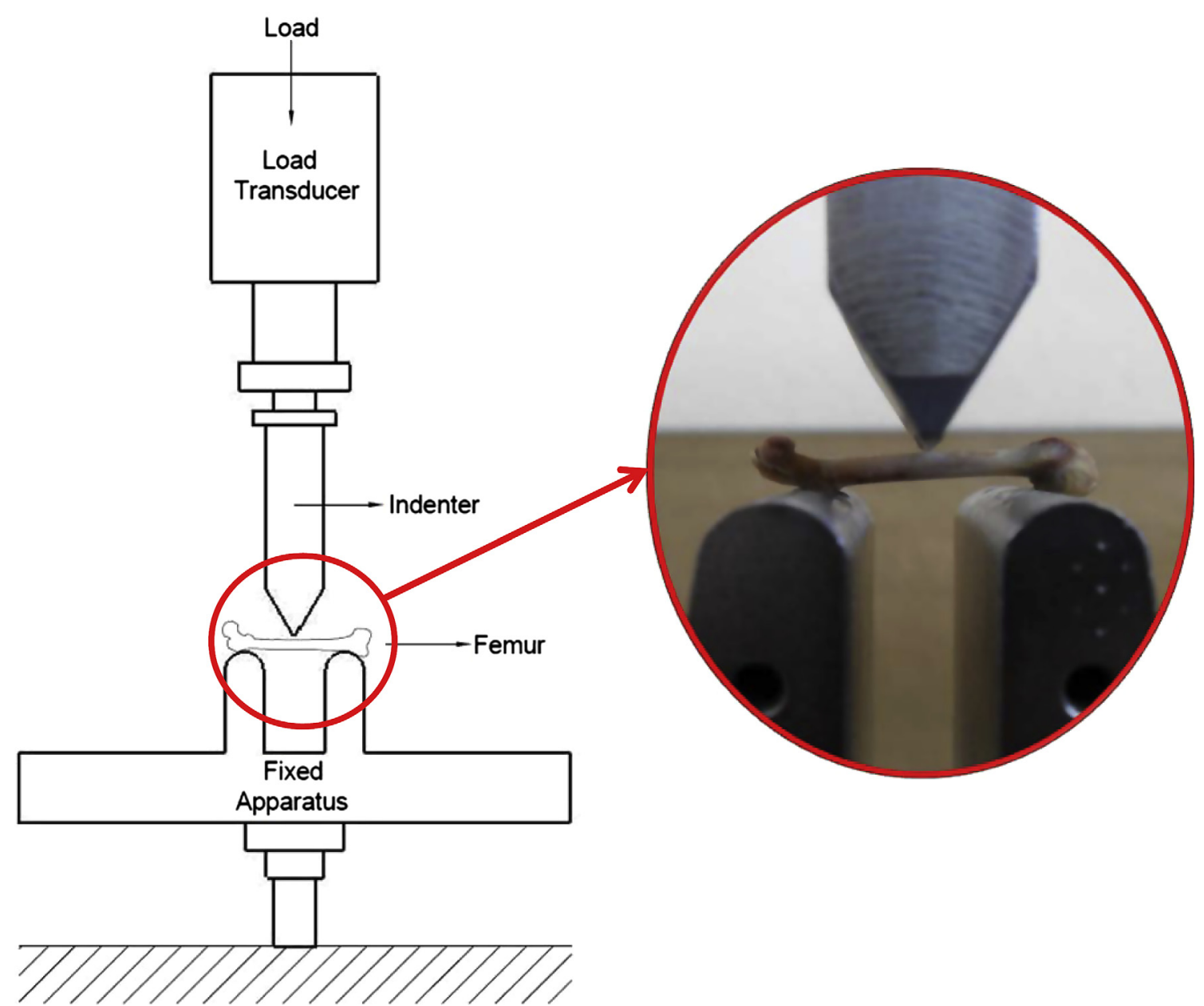

Figure 3. Metaphysis bending test setup.

Table 1. Statistical chart for bone mineral densities of groups.

\begin{tabular}{ll}
\hline Groups & $p$ values \\
\hline OVX vs. Sham & $0.033^{*}$ \\
OVX vs. OVX + GEN & $0.001^{*}$ \\
OVX vs. OVX + EST & $0.001^{*}$ \\
OVX vs. OVX + EST/PROG & $0.007^{*}$ \\
OVX + GEN vs. OVX + EST & $0.001^{*}$ \\
OVX + G vs. OVX + EST/PROG & $0.001^{*}$ \\
OVX + E vs. OVX + EST/PROG & 0.9 \\
\hline
\end{tabular}

* Significant difference.

OVX; Ovariectomized, GEN; Genistein, EST; Estrogen, PROG; Progesteron.

\section{Results}

The genistein group had the highest DEXA value with $0.161 \mathrm{~g} / \mathrm{cm}^{2}$, while the OVX group had the lowest value with $0.128 \mathrm{~g} / \mathrm{cm}^{2}$. The bone mineral density (BMD) values for the sham, OVX + EST, and OVX + EST/PROG groups were $0.140 \mathrm{~g} / \mathrm{cm}^{2}, 0.145 \mathrm{~g} / \mathrm{cm}^{2}$, and $0.143 \mathrm{~g} / \mathrm{cm}^{2}$, respectively. The genistein group showed statistically significant difference compared to the other groups (Table 1).
Table 2. Results of diaphysis bending test.

\begin{tabular}{lccllc}
\hline Groups & \multicolumn{2}{c}{ Peak load $(\mathrm{N})$} & & \multicolumn{2}{c}{ Stiffness $(\mathrm{N} / \mathrm{mm})$} \\
\cline { 2 - 3 } \cline { 6 - 6 } & Mean & Std. & & Mean & Std. \\
\hline Sham & 99.4 & 7.54 & & 242.1 & 48.53 \\
OVX & 88 & 11.4 & & 214.9 & 39.28 \\
OVX + EST & 97.4 & 14.28 & & 223 & 66.76 \\
OVX + EST/PROG & 103 & 6.89 & & 237.1 & 20.53 \\
OVX + GEN & 97.4 & 9.89 & & 211.8 & 51.64 \\
\hline
\end{tabular}

OVX; Ovariectomized, GEN; Genistein, EST; Estrogen, PROG; Progesteron.

In both diaphysis and metaphysis bending tests, the sham group provided better results for the peak load and stiffness compared to the OVX groups as expected (Tables 2 and 3).

In diaphysis and metaphysis bending tests, the treatment groups had higher peak load values than the OVX group (Tables 2 and 3). There were statistically significant differences between the OVX + EST/PROG groups and OVX group in the diaphysis bending test regarding peak load $(p=0.03)$ but no statistically significant difference between all the treatment groups (Table 5). When comparing the stiffness values for the diaphysis bending test, the highest peak load was provided 
Table 3. Results of metaphysis bending test.

\begin{tabular}{llrllr}
\hline Groups & \multicolumn{2}{c}{ Peak load $(\mathrm{N})$} & & \multicolumn{2}{c}{ Stiffness $(\mathrm{N} / \mathrm{mm})$} \\
\cline { 2 - 3 } & Mean & Std. & & Mean & Std. \\
\hline Sham & 46 & 10.58 & & 68.4 & 17.81 \\
OVX & 34.6 & 4.56 & & 30.2 & 7.89 \\
OVX + EST & 47.2 & 7.66 & & 47.4 & 14.65 \\
OVX + EST/PROG & 42.4 & 8.53 & & 46.6 & 16.58 \\
OVX + GEN & 37 & 5.92 & & 50 & 11.5 \\
\hline
\end{tabular}

OVX; Ovariectomized, GEN; Genistein, EST; Estrogen, PROG; Progesteron.

Table 4. Results of axial rotation test.

\begin{tabular}{lllllr}
\hline Groups & \multicolumn{2}{c}{$\begin{array}{c}\text { Peak torque } \\
(\mathrm{N} \mathrm{m})\end{array}$} & & \multicolumn{2}{c}{$\begin{array}{c}\text { Angle at peak } \\
\text { torque }\left(^{\circ}\right)\end{array}$} \\
\cline { 2 - 3 } & Mean & Std. & & Mean & Std. \\
\hline Sham & 0.35 & 0.08 & & 12.52 & 3.81 \\
OVX & 0.30 & 0.05 & & 13.93 & 5.01 \\
OVX + EST & 0.38 & 0.08 & & 13.49 & 3.17 \\
OVX + EST/ & 0.32 & 0.06 & & 15.61 & 7.32 \\
$\quad$ PROG & & & & \\
OVX + GEN & 0.36 & 0.11 & & 19.21 & 5.91 \\
\hline
\end{tabular}

OVX; Ovariectomized, GEN; Genistein, EST; Estrogen, PROG; Progesteron.

by the sham group with the value of $242.1 \mathrm{~N} / \mathrm{mm}$. There were no significant differences between the groups (Table 5).

The results for the metaphysis bending test for each group are shown in Table 4. There were statistically significant differences between the OVX + EST and OVX groups in diaphysis bending regarding peak load $(p=0.01)$ but no statistically significant difference between other groups (Table 5). Additionally, the highest stiffness value was exhibited by the sham group with $68.4 \mathrm{~N} / \mathrm{mm}$ and the lowest stiffness value was $30.2 \mathrm{~N} / \mathrm{mm}$ provided by the OVX group (Table 3 ). There was statistically significant difference between OVX + PROG and OVX groups in terms of stiffness $(p=0.01)$.

In the axial rotation test, all groups had higher peak torque values than the OVX group (Table 4). However, significant difference was only seen between the OVX + EST and the OVX groups for peak torque values $(p=0.02)$. All treated groups exhibited the highest angles at peak torque with values of $19.21^{\circ}$. There were statistically significant differences between the groups (Table 5).

\section{Discussion}

This study showed that the metaphysis and diaphysis bending and axial rotation tests in ovariectomized rat femurs suggested that the use of GEN, EST, and EST/PROG hormones improved the biomechanical properties of the bone.

Osteoporosis reduces bone mass and causes fractures that require complex surgeries [5]. Estrogen replacement therapy is effective in reducing or reversing bone loss [2, 20, 21]. However, ERT is associated with higher risk for breast, ovarian, and endometrial cancer [6-9]. GEN, an isoflavone that is found abundantly in soybeans and their derivative food, could represent a natural alternative to ERT. Epidemiologic data indicate that women ingesting high amounts of phytoESTs, particularly isoflavones in soy products, have less menopausal symptoms than those on Western diets, and consequently, bone density may be favorably influenced by phytoestrogens $[6,7]$. Previous studies have shown that treatment with pure GEN aglycone increased bone mineral density (BMD) at the lumbar spine and femoral neck in postmenopausal women with no clinically significant adverse effects on the breast and uterus [13, 14]. Albertazzi has suggested that GEN aglycone would be a potentially useful, oral, bone anabolic agent [9]. In a study by Bitto et al., GEN aglycone showed a positive effect on osteoporotic bone in the ovaryectomized rat model [19]. They showed decreasing osteoclastic resorption and increasing osteoblastic formation markers. The authors also demonstrated that genistein improved the breaking strength of the femur in the three-point bending test of the femur.

In the present study, the effect of the EST, GEN, and EST/ PROG on the biomechanical properties of the femur was evaluated using not only the diaphysis bending test but also metaphysis bending and axial rotation tests. In the diaphysis bending test, all treated groups had higher peak load values and stiffness than the OVX group. There were no significant differences between the OVX group and other groups for peak load. Diaphysis bending test results showed that administration

Table 5. Statistical chart with $p$ values for biomechanical tests.

\begin{tabular}{lcccc}
\hline \multicolumn{4}{c}{ Statistical chart for biomechanical tests } \\
\hline & OVX vs. Sham & OVX vs. OVX + GEN & OVX vs. OVX + EST & OVX vs. OVX + EST/PROG \\
Peak load (N) & 0.099 & Diaphysis bending test & $0.036^{*}$ \\
Stiffness (N/mm) & 0.358 & 0.201 & 0.283 & 0.293 \\
& & 0.919 & 0.820 & 0.109 \\
Peak load (N) & 0.058 & Metaphysis bending test & $0.013^{*}$ & 0.081 \\
Stiffness $(\mathrm{N} / \mathrm{mm})$ & $0.002^{*}$ & 0.493 & 0.05 & 0.477 \\
Peak torque $(\mathrm{N} \mathrm{m})$ & 0.142 & $0.013^{*}$ & $0.026^{*}$ & 0.619 \\
Angle at peak torque $\left({ }^{\circ}\right)$ & 0.565 & 0.172 & 0.833 & \\
\hline
\end{tabular}

* Significant difference.

OVX; Ovariectomized, GEN; Genistein, EST; Estrogen, PROG; Progesteron. 
of the EST, GEN, and EST/PROG increased the bone strength of the ovariectomized rats. The diaphysis bending test results also showed that there were no statistically significant differences between the OVX group and other groups for stiffness.

In the metaphysis bending test, all treated groups exhibited higher peak load and stiffness values than the OVX group. For peak load, there were no significant differences between the OVX group and other groups, except the OVX and OVX + EST treated groups $(p=0.01)$. For stiffness, the OVX + GEN treated group provided significantly higher values than the OVX group $(p=0.01)$.

In the axial rotation test, the only significant difference in the peak torque was between the OVX and OVX + EST group $(p=0.02)$. The angle at peak torque may be interpreted as the flexibility of the bone in the direction of axial rotation. There were also no significant differences in the angles at peak torque between the OVX and other groups (for all comparisons, $p>0.05$ ). Although there were no significant differences for angle values, the OVX + GEN treated group may be interpreted as the most flexible one (Table 4).

In Miao's study [22], it was noted that GEN had the restoring effect on the BMD in the bilaterally OVX rats. In the present study, the positive effect of the GEN treatment on the bone quality was also confirmed. Furthermore, GEN group had a significantly better effect on the BMD than the EST and EST/PROG groups (for both comparisons, $p=0.001$ ).

This study has some limitations. Firstly, the different doses of substances were not tested; however, the food concentrations were chosen based on the results of previous studies. Secondly, the trabecular microarchitecture of the bone was not analyzed.

\section{Conclusions}

The metaphysis and diaphysis bending and axial rotation tests suggested that the use of GEN, EST, and EST/PROG hormones improved the biomechanical properties of the ovariectomized rat bone. Although all hormone treatments improved DEXA results, GEN provided better DEXA results when compared to both EST and EST/PROG hormones. Genistein may be considered as an alternative to ERT in the treatment of postmenopausal osteoporosis.

\section{Conflict of interest}

The authors declare no conflict of interest in relation with this paper.

\section{References}

1. Ahlborg HG, Johnell O, Nilsson BE, Jeppsson S, Rannevik G, Karlsson MK (2001) Bone loss in relation to menopause: a prospective study during 16 years. Bone 28(3), 327-331.

2. Lindsay R, Hart DM, Aitken JM, MacDonald EB, Anderson JB, Clarke AC (1976) Long-term prevention of postmenopausal osteoporosis by oestrogen. Evidence for an increased bone mass after delayed onset of oestrogen treatment. Lancet 307, 1038-1040.

3. Grady D, Gebretsadik T, Kerlikowske K, Ernster V, Petitti D (1995) Hormone replacement therapy and endometrial cancer risk: a meta-analysis. Obstet Gynecol 85(2), 304-313.

4. Persson I, Adami HO, Bergkvist L et al. (1989) Risk of endometrial cancer after treatment with oestrogens alone or in conjunction with progestogens: esults of a prospective study. British Med J 298, 147-151.

5. Eser O, Aslan A, Coşar M, Kalkan E, Albayrak R (2010) Kyphoplasty method for the treatment of traumatic osteoporotic vertebral compression fractures: case report. Ulus Travma Acil Cerrahi Derg 16(1), 95-97.

6. Horiuchi T, Onouchi T, Takahashi M, Ito H, Orimo H (2000) Effect of soy protein on bone metabolism in postmenopausal Japanese women. Osteoporos Int 11, 721-724.

7. Anderson JJ, Anthony MS, Cline JM, Washburn SA, Garner SC (1999) Health potential of soy isoflavones for menopausal women. Public Health Nutr 2, 489-504.

8. Tsuang YH, Chen LT, Chiang CJ et al. (2008) Isoflavones prevent bone loss following ovariectomy in young adult rats. J Orthop Surg Res 3, 12.

9. Albertazzi P (2002) Purified phytoESTs in postmenopausal bone health: is there a role for GEN? Climacteric 5, 190-196.

10. Pike MC, Peters RK, Cozen W et al. (1997) Estrogen-progestin replacement therapy and endometrial cancer. J Natl Cancer Inst 89(15), 1110-1116.

11. Weiderpass E, Adami HO, Baron JA et al. (1991) Risk of endometrial cancer following estrogen replacement with and without progestins. J Natl Cancer Inst 91(1), 1131-1137.

12. Pike MC, Ross RK (2000) Progestins and menopause: epidemiological studies of risks of endometrial and breast cancer. Steroids 65(10-11), 659-664.

13. Morabito N, Crisafulli A, Vergara C et al. (2002) Effects of genistein and hormone-replacement therapy on bone loss in early postmenopausal women: a randomized double blind placebo-controlled study. J Bone Miner Res 17, 1904-1912.

14. Marini H, Minutoli L, Polito F et al. (2007) Effects of the phytoestrogen genistein on bone metabolism in osteopenic postmenopausal women: a randomized trial. Ann Intern Med 146, 839-847.

15. Harrison E, Adjei A, Ameho C, Yamamoto S, Kono S (1997) The effect of soybean protein on bone loss in a rat model of postmenopausal osteoporosis. J Nutr Sci Vitaminol 44, 257-268.

16. Arjmandi BH, Alekel L, Hollis BW et al. (1996) Dietary soybean protein prevents bone loss in an ovariectomized rat model of osteoporosis. J Nutr 126, 161-167.

17. Kuiper GG, Lemmen JG, Carlsson B et al. (1998) Interaction of estrogenic chemicals and phytoestrogens with estrogen receptor B. Endocrinology 139, 4252-4263.

18. Sehmisch S, Uffenorde J, Maehlmeyer S, Tezval M, Jarry H, Stuermer KM, Stuermer EK (2010) Evaluation of bone quality and quantity in osteoporotic mice - the effects of genistein and equol. Phytomedicine 17(6), 424-430.

19. Bitto A, Burnett BP, Polito F et al. (2008) Effects of GEN aglycone in osteoporotic, ovariectomized rats: a comparison 
with alendronate, raloxifene and oestradiol. Br J Pharmacol 155, 896-905.

20. Huang AJ, Ettinger B, Vittinghoff E, Ensrud KE, Johnson KC, Cummings SR (2007) Endogenous estrogen levels and the effects of ultra-low-dose transdermal estradiol therapy on bone turnover and BMD in postmenopausal women. J Bone Miner Res 22(11), 1791-1797.
21. Ettinger B (2007) Rationale for use of lower estrogen doses for postmenopausal hormone therapy. Maturitas 57(1), 81-84.

22. Miao Q, Li JG, Miao S et al. (2012) The bone-protective effect of genistein in the animal model of bilateral ovariectomy: roles of phytoestrogens and PTH/PTHR1 against post-menopausal osteoporosis. Int J Mol Sci 13(1), 56-70.

Cite this article as: Azboy İ, Özkaya M, Demir T, Demirtaş A, Arslan AK, Özkul E, Akcan A \& Tolunay T (2016) Biomechanical properties of osteoporotic rat femurs after different hormonal treatments: genistein, estradiol, and estradiol/progesterone. SICOT J, 2, 24 